\title{
Verba Bahasa Tontemboan (Suatu Sumbangan Bagi Pembelajaran Bahasa Daerah di Kabupaten Minahasa Selatan)
}

\author{
Rivka Mundung, Nikolas Pesik, Jansen Lintjewas \\ Jurusan Pendidikan Bahasa dan Sastra Indonesia, Fakultas Bahasa dan Seni Universitas Negeri \\ Manado
}

mundungrivka770@gmail.com,nikolaspesik@gmail.com,jansenlintjewas@gmail.com

\begin{abstract}
Abstrak. Masalah dalam penelitian ini ialah verba Bahasa Tontemboan khususnya verba berimbuhan. Tujuan penelitian ini adalah untuk mendeskripsikan verba berimbuhan dalam bahasa Tontemboan ditinjau dari segi bentuk dan maknanya. Pengumpulan data dalam penelitian ini dilakukan dengan memakai tiga teknik yaitu partisipan, wawancara dengan informan (native speaker), dan studi dokumentasi. Metode yang digunakan pada penelitian ini adalah deskriptif kualitatif. Yang menjadi sumber data adalah penutur asli yang berjumlah 3 orang. Hasil dari penelitian ini menunjukkan bahwa verba berimbuhan dalam bahasa Tontemboan dapat berupa: a. verba berupa prefiks /ma-/ contoh /mawdra'/ 'bermain',/marender/ 'memarahi'; /mə-/ contoh /maroma?/ 'berunding', /mərender/ 'bertengkar'; /məka-/ contoh /məkatembo/ 'saling melihat dari ketinggian', /məkatimboy/ 'memegang'; /məpa-/ contoh /məpacma?/ 'membuatkan', /məpatagas/ 'mengeringkan': b. verba berupa infiks /-əm-/ contoh /təmunu/ 'membakar', /samombayay/ 'berdoa'; /-um-/ contoh /kuməsot/ 'keluar',/tumawoy/ 'bekerja'; /-in-/ contoh /sincpa/ 'ditangkap', /tinimboy/ 'dipegang': c. verba berupa sufiks /-an/ contoh /konda?an/ 'langkahi', /wuka?an/ 'bukakan'; /-ən/ contoh /wulcyən/'dipikul', /turu?ən/ 'tunjukkan': d. verba berupa gabungan imbuhan /mə-an/ contoh /məntemboan/ 'saling melihat dari ketinggian', /mənroma?an/ 'saling berbicara'; /pa-ən/contoh /patu?ulən/ 'disebutkan', /pasusuyən/ 'diajari'; /pa-an/ contoh /pawolaran/'dilebarkan', /patimboyan/ 'dipegangi'; /-in-an/ contoh /kinacrean/ 'ditemukan', /tinəkəlan/'ditiduri'. Penelitian ini harus terus dikembangkan agar dapat membantu masyarakat untuk tetap melestarikan bahasa Tontemboan.
\end{abstract}

Kata Kunci: Verba, Bahasa Tontemboan

\section{PENDAHULUAN}

Indonesia merupakan salah satu negara kepulauan terbesar di dunia yang memiliki bermacammacam suku atau kelompok etnis. Tiap kelompok etnis memiliki bahasa daerahnya. Bahasa daerah merupakan salah satu unsur kebudayaan dan berfungsi sebagai lambang kebanggaan daerah, lambang identitas daerah dan alat perhubungan di dalam keluarga dan masyarakat sebagaimana yang dijelaskan dalam UUD 45 Bab XV Pasal 36, menyatakan bahwa "Bahasa daerah merupakan bagian dari kebudayaan Indonesia yang hidup; bahasa daerah itu adalah salah satu unsur kebudayaan nasional yang dilindungi oleh negara" dan berfungsi sebagai 1) lambang kebanggaan daerah, 2) lambang identitas daerah, dan 3) alat perhubungan di dalam keluarga dan masyarakat daerah. Selanjutnya UUD 1945 pasal 32 ayat 2 menegaskan bahwa "Negara menghormati dan memelihara bahasa daerah sebagai kekayaan budaya nasional".

Secara garis besar, penduduk di Sulawesi Utara terdiri atas 3 suku besar, yakni suku Minahasa, suku Sangihe dan Talaud, suku Bolaang Mongondow. Ketiga suku atau etnis besar tersebut memiliki subetnis yang memiliki bahasa dan tradisi yang berbeda-beda. Adapun bahasa daerah yang terdapat di Provinsi Sulawesi Utara yaitu bahasa Tombulu, Tonsea, Tontemboan, Tonsawang, Toulour, Pasan Ratahan, Ponosakan dan Bantik (dari daerah Minahasa), Sangir, Siau, Talaud (dari daerah Sangihe dan Talaud) dan Mongondow, Bolaang, Bintauna, Lolak, Boroko/Bolangitang, Bolango, Bantik Mongondow, Kaidipang (di daerah Bolaang Mongondow). (Usup. H.T. 1981). 
Bahasa Tontemboan merupakan salah satu bahasa daerah yang memiliki penutur yang paling banyak di Minahasa. Bahasa ini digunakan oleh satu sub-etnis Minahasa yang bermukim di daerah wilayah Minahasa Selatan antara lain desa Kumelembuai.

Setiap bahasa, termasuk bahasa daerah di Indonesia memiliki sistem bahasanya sendiri. Beberapa bahasa memiliki sistem bahasa yang sama atau mirip karena mempunyai sistem yang khas dan spesifik bahkan unik, demikian pula terhadap verba (kata kerja) dalam bahasa Tontemboan. Verba (kata kerja) dapat dianggap sebagai suatu masalah yang paling sentral dalam bidang morfologis. Maka dari itu, peneliti ingin melakukan penelitian dalam hal ini sistem pembentukan verba (kata kerja) dalam bahasa daerah Tontemboan khususnya bahasa daerah Tontemboan yang dipakai oleh masyarakat daerah yang berada di Kabupaten Minahasa Selatan, Kecamatan Kumelembuai, lebih khusus di desa Kumelembuai Dua. Desa Kumelembuai Dua dipilih atas pertimbangan bahwa desa tersebut memiliki jumlah masyarakat penutur asli bahasa Tontemboan.

Diharapkan dengan penelitian ini dapat dilihat sejauh mana penggunaan sistem dan pembentukan verba (kata kerja) dalam bahasa daerah Tountemboan, dan dapat juga menjadi suatu kajian bagi pembelajaran bahasa daerah di Kabupaten Minahasa Selatan.

\section{METODE}

Metode penelitian yang digunakan yaitu metode kualitatif deskriptif. Kualitatif deskriptif dapat diartikan sebagai prosedur pemecahan masalah yang diselidiki dengan menggambarkan keadaan subjek atau objek dalam penelitian dapat berupa orang, lembaga, masyarakat dan yang lainnya yang pada saat sekarang berdasarkan fakta-fakta yang tampak atau apa adanya.

Menurut Nazir (1988: 63) dalam Buku Contoh Metode Penelitian, metode deskriptif merupakan suatu metode dalam meneliti status sekelompok manusia, suatu objek, suatu set kondisi, suatu sistem pemikiran ataupun suatu kelas peristiwa pada masa sekarang. Motede ini bertujuan untuk melukiskan

secara sistematis, faktual sesuai dengan karakteristik bidang morfologi. Metode pengambilan data digunakan adalah metode simak dilakukan dengan menyimak penggunaan bahasa (Mahsun, 2012:92) dengan teknik catat.

Partisipasi merupakan salah satu bentuk cara mencari data utama atau informasi dalam metode penelitian kualitatif. Cara melakukan mengumpulkan data ialah melalui keterlibatan langsung dengan obyek yang diteliti. Jika obyek tersebut merupakan masyarakat atau kelompok individu maka peneliti harus berbaur dengan yang diteliti (immersion) sehingga peneliti dapat mendengar, melihat dan merasakan pengalaman-pengalaman yang dialami oleh obyek yang sedang diteliti.

Metode penelitian ini adalah kualitatif, dengan teknik wawancara menjadi metode pengumpulan data yang utama. Esteberg dalam (Sugiyono, 2015 : 317) wawancara merupakan pertemuan dua orang untuk bertukar informasi dan ide melalui tanya jawab, sehingga dapat dikonstruksikan makna dalam suatu topik tertentu. Pengambilan data menggunakan teknik wawancara dalam penelitian ini diharapkan mampu untuk mendapatkan data secara mendalam terkait verba (kata kerja) dalam bahasa daerah Tountemboan.

Dokumen merupakan catatan peristiwa yang sudah berlalu. Metode ini digunakan untuk mencari data mengenai hal-hal atau variabel yang berupa catatan, transkrip, buku, surat kabar, majalah, prasasti, notulen rapat, lengger, agenda dan sebagainya (Suharsimi 2013: 274). Studi dokumen merupakan pelengkap dari penggunaan metode partisipasi dan wawancara dalam penelitian kualitatif.

Teknik analisis data yang digunakan dalam penelitian ini menggunakan Item and Process (Matthew, 1997:18). Pendekatan dalam analisis bahasa yang mendeskripsikan bahasa sebagai suatu sistem yang dinamis, yaitu dengan memperlakukan satu unsur sebagai bentuk asal yang menurunkan bentuk lain melalui deretan perubahan yang dapat digambarkan dengan kaidah-kaidah.

Sumber data dalam penelitian ini yaitu data primer dan sekunder. Data primer berupa hasil wawancara yang diperoleh peneliti dari informan yang dapat dicatat, karena penelitian ini dilakukan di lingkungan masyarakat, tepatnya di desa Kumelembuai II, kecamatan Kumelembuai kabupaten Minahasa Selatan. Untuk itu yang menjadi informan adalah beberapa anggota masyarakat yang berjumlah 3 orang. Data sekunder berupa data-data yang sudah tersedia dalam bentuk teks : dokumen, 
Alkitab perjanjian baru Bahasa Tontemboan (Lembaga Alkitab Indonesia; Jakarta 2018), buku lagu rohani "Kakantaren Paumungan Im Paemanan E Ma Tontemboan Wo Se Tonsea" (BP Sinode GMIM di Tomohon), dan gambar-gambar foto". Instrumen dalam penelitian ini dapat dilihat pada lampiran pertama.

Penelitian ini dilakukan di desa Kumelembuai II, Kecamatan. Kumelembuai, Kabupaten. Minahasa Selatan, Sulawesi Utara. Penelitian ini dilaksanakan selama semester ganjil ditahun ajaran 2019/2020, yaitu pada bulan Juli - Agustus 2019.

\section{HASIL}

Hasil data yang diperoleh dari informan dapat dilihat pada tabel Verba (kata kerja. Tabel Verba (kata kerja) Bahasa Tontemboan

\begin{tabular}{|c|c|c|}
\hline No & $\begin{array}{l}\text { Bahasa } \\
\text { Tontemboan }\end{array}$ & $\begin{array}{l}\text { Bahasa } \\
\text { Indonesia }\end{array}$ \\
\hline $\begin{array}{l}1 . \\
2 . \\
3 . \\
4 . \\
5 . \\
6 . \\
7 . \\
8 . \\
9 . \\
10 . \\
11 . \\
12 . \\
13 . \\
14 . \\
15 . \\
16 . \\
17 . \\
18 . \\
19 .\end{array}$ & 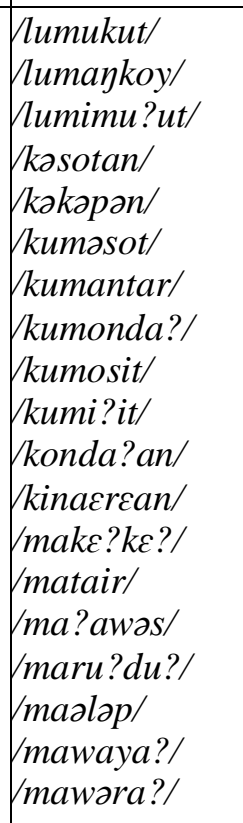 & $\begin{array}{l}\text { 'duduk' } \\
\text { 'melewati' } \\
\text { 'berkeringat' } \\
\text { 'keluarkan' } \\
\text { 'dipeluk' } \\
\text { 'keluar' } \\
\text { 'menyanyi' } \\
\text { 'melangkah' } \\
\text { 'melompat' } \\
\text { 'ikut' } \\
\text { 'langkahi' } \\
\text { 'ditemukan' } \\
\text { 'tertawa' } \\
\text { 'menjaga' } \\
\text { 'bertambah' } \\
\text { 'menyuruh' } \\
\text { 'sedang minum' } \\
\text { 'berjalan' } \\
\text { 'bermain' }\end{array}$ \\
\hline $\begin{array}{l}20 . \\
21 . \\
22 . \\
23 . \\
24 . \\
25 . \\
26 . \\
27 . \\
28 . \\
29 . \\
30 . \\
31 . \\
32 . \\
33 . \\
34 . \\
35 . \\
36 . \\
37 .\end{array}$ & 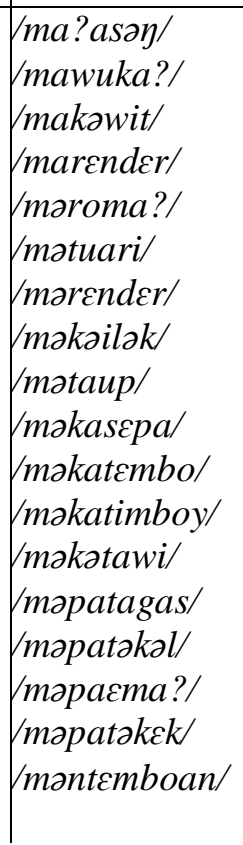 & $\begin{array}{l}\text { ‘bernafas' } \\
\text { 'membuka' } \\
\text { ‘berbisik' } \\
\text { 'memarahi' } \\
\text { ‘berunding', } \\
\text { ‘bersaudara' } \\
\text { ‘bertengkar' } \\
\text { 'tahu’ } \\
\text { ‘bertemu' } \\
\text { 'dapat ditangkap' } \\
\text { 'melihat' } \\
\text { 'memegang' } \\
\text { 'berdekatan' } \\
\text { 'mengeringkan' } \\
\text { 'menidurkan' } \\
\text { 'membuatkan' } \\
\text { 'membuat jadi kecil' } \\
\text { 'saling melihat dari } \\
\text { ketinggian' }\end{array}$ \\
\hline
\end{tabular}




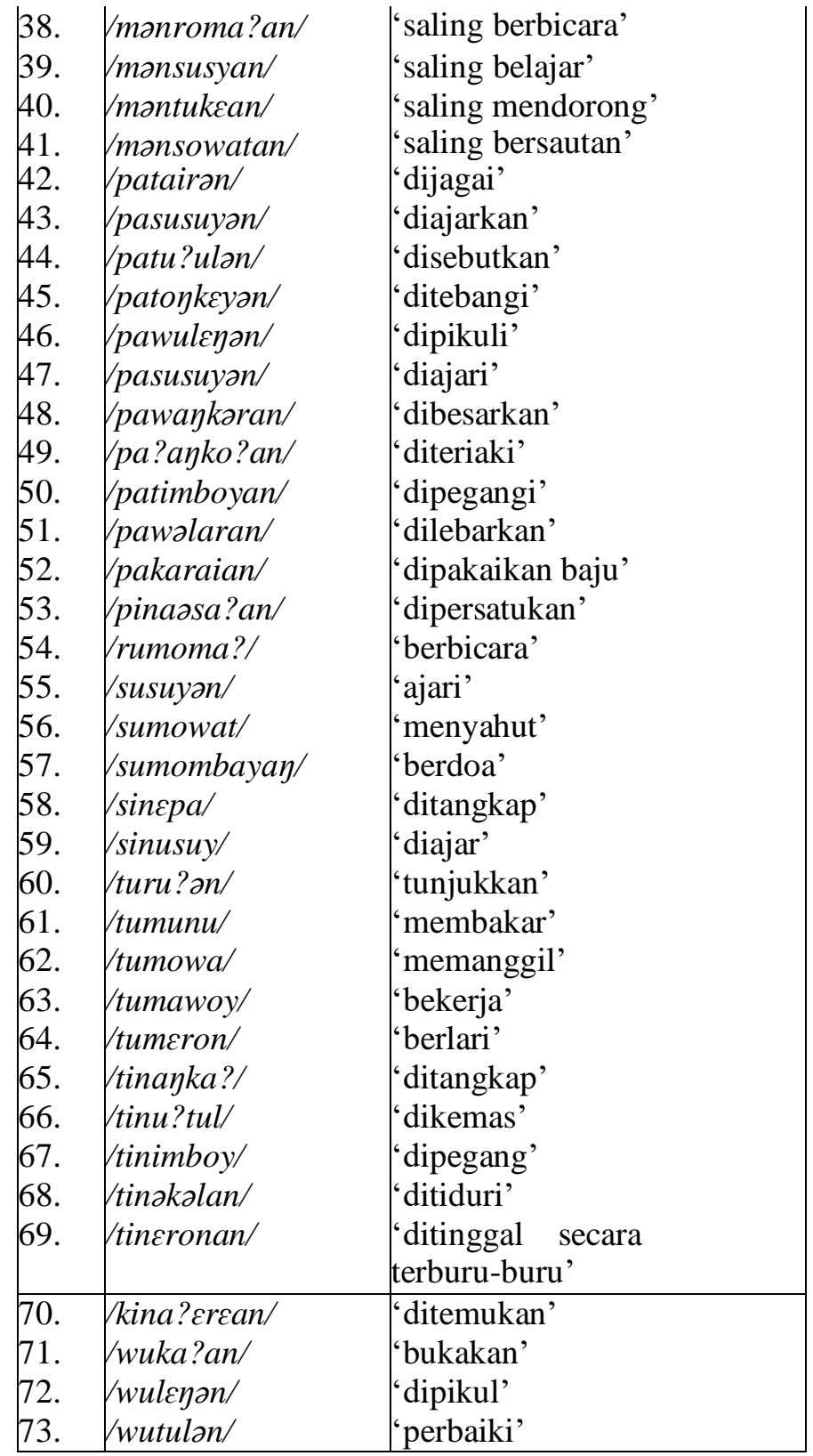

\section{Bentuk Verba (kata kerja) Berimbuhan dalam Bahasa Tontemboan}

Kata kerja berimbuhan terdiri dari prefiks : /ma-/ ; /mə-/ ; /məka-/ ; /məpa-/, sufiks : /-an/ ; /-ən/, infiks : /-əm-/ ; /-um-/ ;/-in-/, gabungan imbuhan :/mə-an/ ;/pa-ən/ ; /pa-an/ ; /-in-an/.

\section{Prefiks}

Prefiks /ma-/

Dari segi bentuk apabila prefiks /ma-/ melekat pada bentuk dasar maka tidak mengalami perubahan.

Contoh :

$/$ ma-/+/waya?//mawaya?/'berjalan'

$/$ ma-/+/render/ $\rightarrow /$ marender/'memarahi'

/ma-/+/wəra?/ $\rightarrow$ /mawəra?/'bermain'

Prefiks /mə-/

Dari segi bentuk apabila prefiks /mə-/ melekat pada bentuk dasar maka tidak mengalami perubahan. 


\section{Contoh :}

$/$ mə-/+/roma?/ $\rightarrow /$ məroma?/'berunding' $/ \mathrm{m} ə /+/$ render $/ \rightarrow /$ mərender/'bertengkar' $/ \mathrm{m} ə-/+/$ taup/ $\rightarrow /$ mətaup/“bertemu'

Prefiks /məka-/

Dari segi bentuk apabila prefiks /məka-/ melekat pada bentuk dasar maka tidak mengalami perubahan.

Contoh :

$/ \mathrm{moka}-/+/ \mathrm{tcmbo} / \rightarrow /$ məkatembo/ 'melihat'

/məka-/+/timboy/ $\rightarrow /$ məkatimboy/ 'memegang'

/məka-/+/tawi/ $\rightarrow /$ mokatawi/ 'berdekatan'

Prefiks /məpa-/

Dari segi bentuk apabila prefiks /məpa-/ melekat pada bentuk dasar maka tidak memiliki perubahan.

Contoh :

$/$ məpa-/+/tagas/ $\rightarrow /$ məpatagas/ 'mengeringkan'

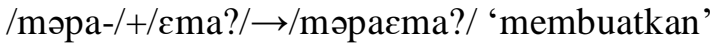

/məpa-/+/to?or/ $\rightarrow$ /məpato?or/ 'menyuruh membangunkan'

\section{Infiks}

Infiks /-um-/

Dari segi bentuk apabila sufiks /-um-/ melekat pada bentuk dasar maka tidak mengalami perubahan.

Contoh :

/-um-/+/kəsot/ $\rightarrow$ /kuməsot/'keluar'

/-um-/+/tawoy/ $\rightarrow /$ tumawoy/'bekerja'

/-um-/+/teron/ $\rightarrow /$ tumeron/'berlari'

Infiks /-in-/

Dari segi bentuk apabila sufiks /-in-/ melekat pada bentuk dasar maka tidak mengalami perubahan.

Contoh :

$/$-in-/+/sepa/ $\rightarrow /$ sinepa/'ditangkap'

$/$-in-/+/timboy/ $\rightarrow /$ tinimboy/'dipegang'

/-in-/+/tanka?/ $\rightarrow /$ tinanka?/‘ditangkap'

\section{Sufiks}

Sufiks /-an/

Dari segi bentuk apabila sufiks /-an/ melekat pada bentuk dasar maka tidak mengalami perubahan.

Contoh :

/-an/+/konda?/ $\rightarrow$ /konda?an/'langkahi'

$/$-an/+/wuka?/ $\rightarrow /$ wuka?an/'bukakan'

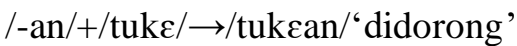

Sufiks /-ən/

Dari segi bentuk apabila sufiks /-ən/ melekat pada bentuk dasar maka tidak mengalami perubahan. Contoh :

/-ən/+/wulen/ $\rightarrow$ /wulcyən/'dipikul'

$/$-ən/+/turu?/ $\rightarrow$ turu? ən/'tunjukkan'

/-ən/+/susuy/ $\rightarrow$ /susuyən/'ajari' 


\section{Gabungan imbuhan}

Gabungan imbuhan /mə-an/

Dari segi bentuk apabila gabungan imbuhan /mə-an/ melekat pada bentuk dasar maka tidak mengalami perubahan.

Contoh :

$/ \mathrm{m} ə-\mathrm{an} /+\mathrm{t}$ embo/ $\rightarrow /$ məntemboan/ 'saling melihat dari ketinggian'

$/ \mathrm{m} ə-\mathrm{an} /+/$ susuy $/ \rightarrow /$ mənsusuyan/'saling belajar'

$/$ mə-an/+/roma?///mənroma?an/ 'saling berbicara'

Gabungan imbuhan /pa-ən/

Dari segi bentuk apabila sufiks /pa-ən/ melekat pada bentuk dasar maka tidak mengalami perubahan. Contoh :

$/$ pa-ən/+/tu?ul/ $\rightarrow /$ patu?ulən/ 'disebutkan'

$/$ pa-ən/ $+/$ susuy/ $\rightarrow /$ pasusuyən/'diajari'

$/$ pa-ən/ +/tair/ $\rightarrow /$ patairən/‘dijagai'

Gabungan imbuhan /pa-an/

Dari segi bentuk apabila sufiks /pa-an/ melekat pada bentuk dasar maka tidak mengalami perubahan.

Contoh :

/pa-an/+/wəlar/ $\rightarrow$ /pawəlaran/ 'dilebarkan'

/pa-an/ +/karai/ $\rightarrow$ /pakaraian/ 'dipakaikan baju'

$/$ pa-an/ +/timboy/ $\rightarrow /$ patimboyan/ 'dipegangi'

Gabungan imbuhan /-in-an/

Dari segi bentuk apabila sufiks /-in-an/ melekat pada bentuk dasar maka tidak mengalami perubahan.

Contoh :

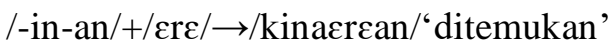

/-in-an/+/təkəl/ $\rightarrow /$ tinəkəlan/'ditiduri'

/-in-an/+/teron/ $\rightarrow /$ tineronan/'ditinggal secara terburu-buru'

\section{Makna Verba (kata kerja) Berimbuhan Bahasa Tontemboan}

\section{Prefiks}

Prefiks /ma-/ bermakna melakukan tindakan dan bersifat aktif

Contoh :

1. /maələp pe? ranoaku/ 'Saya sedang minum air'.

2. /mawaya? kekeyaku/ 'Saya berjalan kaki'.

Prefiks /mə-/ bermakna melakukan tindakan yang dilakukan antara dua orang dan bersifat aktif atau pasif

Contoh :

1. /mərender pe scra/ 'Mereka masih sementara bertengkar'.

2. /yaku wo sia mətaup tarepe?/ 'Saya dan dia bertemu tadi'. Prefiks /məka-/bermakna melakukan tindakan dan bersifat aktif Contoh :

1. /məkatimboy inkamanaaku/ 'Saya memegang tangannya'.

2. /sia məkatemboaku/ 'Dia melihat saya'.

Prefiks /məpa-/ bermakna melakukan tindakan suruhan dan bersifat pasif

Contoh :

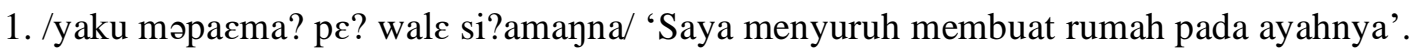

2. /əko məpato?or si?inanmu/ 'Kamu menyuruh membangunkan ibumu'. 


\section{Infiks}

Infiks /-um-/ bermakna melakukan tindakan dan bersifat aktif

Contoh :

1. /tumawoy pe?anumayaku/ 'Saya mau bekerja di kebun'.

2. /yaku kumosit? ambitu/ 'Saya melompat disitu'.

Infiks /-in-/ bermakna melakukan tindakan dan bersifat pasif

Contoh :

1. /tinimboyna kamaku/ 'tanganku dipegangnya'.

2. /tinu?ulna jaranku/ 'namaku disebutnya'.

\section{Sufiks}

Sufiks /-an/ bermakna melakukan tindakan suruhan dan bersifat pasif

Contoh :

1. /wuka?an nio əクkəkələwna/ 'Bukakan penutupnya'.

2. /tukean nio anpəpalən/ 'Didorong pintunya'.

Sufiks /-ən/ bermakna melakukan tindakan suruhan dan bersifat pasif

Contoh :

1. /pəkituluyan tairən nio toya?ayku/ 'Tolong jagai anak saya'.

2. /turu?ən aylalan waya?anta/ 'Tunjukkan jalan yang akan kita lewati'.

\section{Gabungan imbuhan}

Gabungan imbuhan /mə-an/ bermakna melakukan tindakan yang dilakukan antara dua orang dan bersifat aktif

Contoh :

1. /məntemboan cita indua/'Kita berdua saling melihat dari ketinggian'.

2. /mənsusuyan scra indua/ 'Mereka berdua saling mengajar'.

Gabungan imbuhan /pa-ən/ bermakna melakukan tindakan dan bersifat aktif atau pasif

Contoh :

1. /pawulenənna əクkayu ya?na/ 'Kayu itu dipikulnya'.

2. /patu?ulən əyaranku ando?ony/ 'Namaku disebutkan di kampung'. Gabungan imbuhan /pa-an/ bermakna melakukan tindakan dan bersifat pasif Contoh :

1. /pawəlaran lalan anbitu/ 'Jalan disitu dilebarkan'.

2. /patimboyan nio ə⿹kamana/ 'dipeganggi tangannya'.

Gabungan imbuhan /-in-an/ bermakna melakukan perbuatan dan bersifat pasif

Contoh :

1. /kinacrean'o toya?ay ya?na/ 'Anak itu sudah ditemukan'.

2. /tinəkəlanasu ənpalukutan ya?na/ 'Tempat duduk itu ditiduri seekor anjing'

\section{KESIMPULAN}

Berdasarkan hasil analisis data yang peneliti lakukan dalam penelitian ini, maka dapat disimpulkan sebagai berikut :

Dari segi bentuk, Verba berimbuhan bahasa Tontemboan adalah :

Prefiks /ma-/ seperti pada kata /ma-/+/əlap/ $\rightarrow /$ maəlap/'sedang minum'

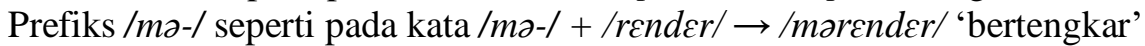

Prefiks /məka-/ seperti pada kata/məka-/ + /timboy/ $\rightarrow$ /məkatimboy/Prefiks /məpa-/ seperti

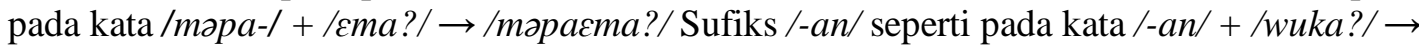
/wuka?an/'bukakan' Sufiks /-ən/ seperti pada kata /-ən/ + /turu?/ $\rightarrow / t u r u ?$ ? $/$ 'bukakan' Infiks 
/-um-/ seperti pada kata /-um-/ + /tawoy/ $\rightarrow$ /tumawoy/ 'bekerja' Infiks /-in-/ seperti pada kata /in $/$ + /tu? ul $\rightarrow /$ tinu? ul/'disebut'

Gabungan imbuhan /mo-an/ seperti pada kata /mo-an/ + /tembo/ $\rightarrow$ /montemboan/'saling melihat dari ketinggian'.

Gabungan imbuhan /pa-ən/ seperti pada kata /pa-ən/ + /tu?ul/ $\rightarrow / p a t u ? u l \partial n /$ 'disebutkan'

Gabungan imbuhan /pa-an/ seperti pada kata /pa-an/ + /wolar/ $\rightarrow$ /pawalaran/'dilebarkan'

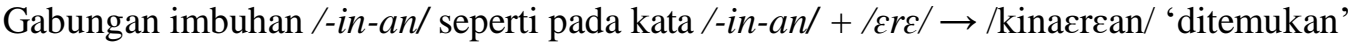

Dari segi makna, Verba berimbuhan bahasa Tontemboan adalah :

Prefiks /ma-/ maknanya membentuk kata kerja melakukan tindakan dan bersifat aktif

Prefiks /mə-/ maknanya membentuk kata kerja melakukan tindakan yang dilakukan antara dua orang dan bersifat aktif atau pasif

Prefiks /məka-/ maknanya membentuk kata kerja melakukan tindakan dan bersifat aktif

Prefiks /mәра-/ maknanya membentuk kata kerja melakukan tindakan suruhan dan bersifat pasif Infiks /-əm-/maknanya membentuk kata kerja melakukan tindakan dan bersifat aktif Infiks /-um/ maknanya membentuk kata kerja melakukan tindakan dan bersifat aktif Infiks /-in-/ maknanya membentuk kata kerja melakukan tindakan dan bersifat pasif

Sufiks /-an/maknanya membentuk kata kerja melakukan tindakan suruhan dan bersifat pasif Sufiks /-ən/ maknanya membentuk kata kerja melakukan tindakan suruhan dan bersifat pasif Gabungan imbuhan /mə-an/ maknanya membentuk kata kerja melakukan tindakan yang dilakukan antara dua orang dan bersifat aktif

Gabungan imbuhan / $p a-\partial n /$ maknanya membentuk kata kerja melakukan tindakan dan bersifat aktif atau pasif

Gabungan imbuhan /pa-an/maknanya membentuk kata kerja melakukan tindakan dan bersifat pasif

Gabungan imbuhan /-in-an/ maknanya membentuk kata kerja melakukan perbuatan dan bersifat pasif. 


\section{DAFTAR PUSTAKA}

Kridalaksana, Harimurti. 2009. Kamus Linguistik. Jakarta: Gramedia.

Marali, Amari. 1990.”Metode Kuantitatif dan Kualitatif: saling Melengkapi”. Jurnal Antropologi Totem. Jakarta: jaringan Kekerabatan Antropologi Indonesia. No.1/th. 1. Naroll, R \& Cochen, R. (ed).

Miles, M. B., \& Huberman, M. A. 1994. Qualitative data analysis: an expanded Ilyas /Journal of Nonformal Education, Vol. 2 No 1, Tahun 201698 sourcebook (2rded). London: Sage Publication.

Tarigan, Henry Guntur. 1975. Morfologi Bahasa Simalungun.Jakarta: Universitas Indonesia (disertasi).

Usup. H.T. 1981. Morfologi dan Sintaksis Bahasa Bolaang Mongondow. Pusat Pembinaan dan Pengembangan Bahasa Departemen Pendidikan dan Kebudayaan: Jakarta.

Vredenbergt, J. 1984. Metode dan Teknik Penelitian Masyarakat. Jakarta: Gramedia. 